\title{
Mu-heavy chain disease
}

INSERM

\section{Source}

INSERM. (1999). Orphanet: an online rare disease and orphan drug data base. Mu-heavy chain disease. ORPHA:100024

Mu-heavy chain disease (mu-HCD) is a type of HCD (see this term) characterized by the production of incomplete monoclonal mu-heavy chains without associated light chains.

The clinical presentation resembles that of patients with chronic lymphocytic leukemia/small lymphocytic lymphoma (CLL/SLL; see this term). 